OPEN ACCESS

Edited by:

Shuai Ji,

Xuzhou Medical University, China

Reviewed by:

Yogesh Chandra Tripathi,

Forest Research Institute, India

David M. Pereira,

University of Porto, Portugal

Joshua Kibet,

Egerton University, Kenya

*Correspondence:

Ye Wang

hhyzwy@126.com

Shuihan Zhang

zhangshuihan0220@126.com

Specialty section:

This article was submitted to

Ethnopharmacology,

a section of the journal

Frontiers in Pharmacology

Received: 05 December 2020

Accepted: 25 January 2021

Published: 08 March 2021

Citation:

Zheng Q, Wang Y and Zhang S (2021)

Beyond Alkaloids: Novel Bioactive

Natural Products From

Lobelia Species.

Front. Pharmacol. 12:638210.

doi: 10.3389/fphar.2021.638210

\section{Beyond Alkaloids: Novel Bioactive Natural Products From Lobelia Species}

\author{
Qinfang Zheng ${ }^{1,2}$, Ye Wang ${ }^{2 *}$ and Shuihan Zhang ${ }^{1,3 *}$ \\ ${ }^{1}$ Hunan Academy of Chinese Medicine, Hunan University of Chinese Medicine, Changsha, China, ${ }^{2}$ Key Laboratory of Dong \\ Medical Research of Hunan Province, Hunan University of Medicine, Huaihua, China, ${ }^{3} 2011$ Collaboration and Innovation Center \\ for Digital Chinese Medicine in Hunan, Changsha, China
}

In this work, we reviewed the progress in the phytochemical and biological investigations of bioactive components derived from medicinally valuable Lobelia species. In the last 60 years, Lobelia has garnered significant attention from the phytochemist from around the world, majorly due to the discovery of bioactive piperidine alkaloids (e.g., lobinaline and lobeline) in the early 1950s. Later, lobeline underwent clinical trials for several indications including the treatment of attention deficit hyperactivity disorder and a multicenter phase three trial for smoking cessation. Subsequently, several other alkaloids derived from different species of Lobelia were also investigated for their pharmacological characteristics. However, in the last few years, the research focus has started shifting to the characterization of the other novel chemical classes. The major shift has been noticed due to the structurally similar alkaloid components, which essentially share similar pharmacological, physicochemical, and toxicological profiles. In this review, we present an up-to-date overview of their progress with special attention to understanding the molecular mechanisms of the novel bioactive components.

Keywords: lobelia, alkaloids, natural products, lobeline, bioactive compounds

\section{INTRODUCTION}

Lobelia, named after the botanist Matthias de lobel, is a large genus of medicinally valuable flowering plants belonging to the Campanulaceae family comprising more than 450 species distributed predominantly in tropical and temperate regions of the world. Several species of Lobelia are traditionally used in different folk medicine to treat various diseases. Among them, Lobelia inflata, Lobelia nicotianaefolia, Lobelia cardinalis, Lobelia chinensis, Lobelia laxiflora, Lobelia trigona Roxb., Lobelia siphilitica L., Lobelia sessilifoilia Lamb, Lobelia polyphylla, and Lobelia pyramidalis Wall. are some of the frequently used Lobelia species. The phytochemical researches of these species led to the discovery of several novel bioactive secondary metabolites.

The earliest scientific report on the pharmacological use of Lobelia species in diseased conditions dates back to 1828 (Andrew, 1828). More than a century later (in 1950), Tondeur and Charlier reported the extraction and pharmacological activities of alkaloids from Lobelia suavibracteata (Haumann) and Lobelia giberroa (Hemsl.) (Charlier and Tondeur, 1950; Tondeur and Charlier, 1950). In the 1950s, other studies began to reveal the distinctive pharmacological properties of the alkaloid constituents derived from different Lobelia species (Lendle and Richter, 1950). One of the alkaloids that garnered major attention was lobeline 1 (Figure 1), which was primarily derived from the aerial parts of Lobelia inflata, (Kaczmarek and Steinegger, 1959; Saldanha et al., 1959). In the 
subsequent decades, the studies on the prospective evaluation of the use of lobeline have seen unprecedented advances, including but not limited to smoking cessation (Glover et al., 2010; Stead and Hughes, 2012), treatment of drug and alcohol abuse (Bell et al., 2009; Hart et al., 2010; Roni and Rahman, 2017), adult ADHD (Martin et al., 2018), anti-depressant (Roni and Rahman, 2015), anti-epileptic (Tamboli et al., 2012), and Parkinson's disease (Li et al., 2014).

For example, in their study, Roni and Rahman noticed that adult C57BL/6J mice when treated with once daily dose of lobeline $(1 \mathrm{mg} / \mathrm{kg}$, s.c.) in the last 14 days of their exposure to chronic unpredictable stress (CUS) for 6 weeks produced antidepressant-like effects. They proposed targeting brain nicotinic acetylcholine receptors (nAChRs), brain-derived neurotrophic factor (BDNF) expression and/or cell proliferation in the hippocampus to be the most likely cause of the observed antidepressant-like effects of lobeline (Roni and Rahman, 2015). Saline was used as the negative control. Hart et al. reported that at doses of $1.0 \mathrm{mg} / \mathrm{kg}$ and $3.0 \mathrm{mg} / \mathrm{kg}$ subcutaneous injections of lobeline attenuates self-administration of intravenous (i.v.) heroin (3,6 diacetylmorphine $\mathrm{HCl})$ infusions $(18 \mu \mathrm{g} / \mathrm{kg})$ in male Sprague-Dawley rats suggesting their use in pharmacotherapy for opioid abuse (Hart et al., 2010). In both studies, however, they did not make a comparison of the effect of lobeline with any reference standard.

Martin et al. reported the results of a preclinical study in which they studied the effect of lobeline in adult ADHD (Martin et al., 2018). In their study, they subjected a total of nine adults (5 females, 4 males, ages $23-41$ [31.11 \pm 7.08 years]) to a 7 -day protocol of oral administration of methylphenidate capsule $(0,15$, or $30 \mathrm{mg}$, p.o.) followed by sublingual (s.l.) administration of lobeline tablets $(0,7.5,15$, or $30 \mathrm{mg}$, s.l.) after $1 \mathrm{~h}$. Inactive doses of both sublingual and oral formulations were used as placebo. They observed that lobeline could improve working memory in a modest capacity (without significant improvement in their attention) in nine volunteers with ADHD.

Li et al. investigated the effect of s.c administrations of lobeline hydrochloride ( 1 or $3 \mathrm{mg} / \mathrm{kg}$ ) on male $\mathrm{C} 57 \mathrm{BL} / 6 \mathrm{~J}$ mice against methyl-4-phenyl-1,2,3,6-tetra-hydropyridine

(MPTP, $30 \mathrm{mg} / \mathrm{kg})$-induced cell death in vivo using L-dopa $(80 \mathrm{mg} / \mathrm{kg})$ and the potent and selective dopamine reuptake inhibitor, GBR12935 (10 mg/kg) as positive controls (Li et al., 2014). The s.c. injections of lobeline, GBR12935, or L-dopa were done for 11 days $30 \mathrm{~min}$ prior to MPTP administration. They observed that MPTP induced locomotive effects detected in behavioral tests were significantly reduced by lobeline as compared to L-dopa and GBR12935. Further, they observed that the loss of neurotoxin-induced immunoreactivity was significantly reduced in the substantia nigra and striatum regions of the brain. The overall results indicated that lobeline may protect dopaminergic neurons and alleviate the symptoms of Parkinson's disease. Saline was used as the negative control.

Tamboli et al. investigated lobeline isolated from Lobelia nicotianaefolia in chemoconvulsant-induced seizures using diazepam as a reference standard (Tamboli et al., 2012). The anticonvulsant activity of the isolated lobeline was investigated at 5, 10, 20 and $30 \mathrm{mg} / \mathrm{kg}$, intraperitoneal (i.p.) doses in Pentylenetetrazol (PTZ) and strychnine induced seizures in Swiss albino male mice. They found that isolated lobeline induces potent anticonvulsant activity against PTZ induced seizures by enhancing the brain gamma amino butyric acid (GABA) level at $20 \mathrm{mg} / \mathrm{kg}$ i.p. within a duration of $45 \mathrm{~min}$ after their administration. Saline was used as the negative control.

Mechanistically, lobeline was reported binding to the $\alpha 4 \beta 2$ nAChR with nanomolar affinity (Brioni et al., 1997) but with less potent affinity against muscarinic and acetylcholinesterase receptors (Terry et al., 1998). The high-affinity partial agonist property of lobeline against $\alpha 4 \beta 2 \mathrm{nAChR}$ was later identified as the mechanism for smoking cessation (Wu et al., 2006; Billen et al., 2012). Recently, Anitha et al. shed additional light on how smoking cessation by lobeline occurs through trapping in $\alpha 4 \beta 2$ receptors-containing acidic vesicles and how intracellular $\mathrm{pH}$ homeostasis plays a crucial role in it (Govind et al., 2017). Lobeline was also demonstrated to block the blood-brain barrier (BBB) basic amine transporter (Allen et al., 2003), and act as VMAT2 ligand (Zheng et al., 2005; Zheng et al., 2006). In another study, (-)-lobeline hydrochloride monohydrate $(10$ or $20 \mathrm{mg} / \mathrm{kg}$, i.p.) was reported to reduce the DNA damage and oxidative stress induced by seizures in a pilocarpine-induced seizure model on 69 adult male CF-1 mice (da Costa E Silva et al., 2018). The administrations of pilocarpine $(300 \mathrm{mg} / \mathrm{kg})$ were performed after 30 min treatment of lobeline, diazepam (positive control) or saline (negative control).

Overall, to date, more than 610 scientifically peer-reviewed research articles carrying the pharmacological investigation of the pyridine alkaloid lobeline and its structural analogs were reported underlying its medicinal importance. However, the gastrointestinal side effects (due to nicotinic effects), the lethal toxicity due to its narrow therapeutic index, and other adverse side effects such as choking and cough limits the clinical utility of lobeline (Butler et al., 2001; Raj et al., 2005; Stead and Hughes, 2012; Heinzerling, 2013).

\section{Beyond Lobeline: Other Bioactive Alkaloids}

In the early 1950s, the German phytochemist Steinegger and team reported several key discoveries on the identification and pharmacological studies of the newer alkaloids from different Lobelia species. First, they reported the identification of a crystallized alkaloid named lurenine isolated from Lobelia urens (Steinegger and Grutter, 1950). Subsequently, they also identified two new alkaloids lophilin and lophilacrin in the alkaloid fraction of Lobelia siphilitica (Steinegger and Egger, 1952). In the 1950s, other studies began to reveal the distinctive pharmacological properties of the alkaloid constituents identified in different Lobelia species (Lendle and Richter, 1950), which has further raised tremendous interest in phytochemical research. Lobinaline 2, the only alkaloid found in the Lobelia cardinalis L. and the first binitrogenous alkaloid extracted from any Lobelia species was reported having a unique nAChR binding activity (Klosa, 1953; Kaczmarek and Steinegger, 1958; Brown et al., 2016). In addition to their equipotent $\alpha 4 \beta 2$-and $\alpha 7-n A C h R s$ binding profile, the purified lobinaline obtained from $\mathrm{CHCl}_{3}$ fraction of air-dried aerial 
portions of L. cardinalis also exhibited potent 2,2-Diphenyl-1picrylhydrazyl (DPPH) free radical scavenging properties, inhibited in vitro [(3) $\mathrm{H}]$-dopamine uptake in adult male Sprague-Dawley rats striatal synaptosomes, and potent dopamine transporter inhibition (Brown et al., 2016). Reportedly, lobinaline (stock solution: $1 \mathrm{mg} / \mathrm{ml}$ ) scavenge DPPH free radicals with an $\mathrm{EC}_{50}$ of $17.98 \mu \mathrm{M}$ when examined in DPPH (stock solution: $600 \mu \mathrm{M}$ ) free radical scavenging assay. In contrast, lobeline (stock solution: $1 \mathrm{mg} / \mathrm{ml}$ ) demonstrated a weak DPPH free radical scavenging property $\left(\mathrm{EC}_{50}=228.8 \mu \mathrm{M}\right)$. In vivo electrochemical studies indicated that lobinaline in a short acting and likely competitive-capacity inhibits dopamine transporter function in the dorsal striatum of urethaneanesthetized rats. Interestingly, lobinaline $(1 \mathrm{mM})$ was noticed significantly increasing ${ }^{45} \mathrm{Ca}^{2+}$ entry in SH-SY5Y cells.

In 1954, major alkaloids named lobelanidine 3, and lelobanidine 4 were also isolated from Lobelia nicotianaefolia (Gedeon and Gedeon, 1954). Lobelanidine 3 was subsequently identified in Lobelia chinensis exhibiting anticancer and antiemetic properties (Chen et al., 2014). In 2001, two new pyrrolidine alkaloids, radicamines A 5 and radicamines B 6 isolated from the hot water extract of Lobelia chinensis Lour. (Shibano et al., 2001). The basic extract solution $(25 \mu \mathrm{L})$ was were identified exhibiting potent alpha-glucosidase $(100 \mu \mathrm{L})$ inhibition (Shibano et al., 2001). Radicamines A, radicamines B and the positive control $(2 R, 3 R, 4 R, 5 R)$ 2,5-dihydroxymethyl-3,4dihydroxy-pyrrolidine (DMDP) exhibited $\mathrm{IC}_{50}$ of $6.7 \times 10^{-6}$, $9.3 \times 10^{-6}$, and $4.9 \times 10^{-6} \mathrm{M}$, respectively.

In 2015, Paz et al. reported a new alkaloid, pentylsedinine 7, isolated from the fresh aerial parts of Lobelia tupa (Paz et al., 2015). When evaluated against the $\alpha 3 \beta 2 / \alpha 3 \beta 4 \mathrm{nAChR}$ and $\alpha 7$ $\mathrm{nAChR}$ receptors expressed in the human neuroblastoma cell line SH-SY5Y, like lobeline, (-)-pentylsedinine acted as a nonselective partial agonist at homomeric $\alpha 7 \mathrm{nAChR}\left(\mathrm{EC}_{5} \mathrm{O} 0.4 \pm\right.$ $0.08 \mu \mathrm{M})$ and heteromultimeric $\alpha 3 \beta 2 / \alpha 3 \beta 4 \quad\left(\mathrm{EC}_{50} 0.33 \pm\right.$ $0.07 \mu \mathrm{M}) \mathrm{nAChR}$. Interestingly, the co-addition of lobeline and (-)-pentylsedinine desensitized $a 7 \mathrm{nAChR}$ to the response from the selective $\alpha 7 \mathrm{nAChR}$ agonist choline. Apparent $\mathrm{IC}_{50}$ of lobeline and (-)-pentylsedinine were $1.6 \pm 0.4 \mu \mathrm{M}$ and $0.37 \pm 0.08 \mu \mathrm{M}$, respectively.

Lobelane 8, a defunctionalized analog of lobeline exhibited 10-15 fold more potent effects than lobeline in inhibition of the vesicular dopamine (DA) uptake by VMAT2, and inhibited (+)-methamphetamine-evoked DA release (Vartak et al., 2009; Nickell et al., 2010). It was also reported to possess a fivefold binding affinity than lobeline for the dihydrotetrabenazine binding site on VMAT2 (Miller et al., 2004; Zheng et al., 2005). In a study aimed at synthesizing lobelane analogs as therapeutic agents, replacement of the phenyl groups of lobelane with quinolyl groups resulted in a water-soluble analog called quinlobelane nine that possessed stronger VMAT2 inhibition (Vartak et al., 2010).

The phytochemical research conducted over the years suggested that alkaloids are the predominant secondary metabolites $(\sim 46 \%)$ present in most of the Lobelia species known. These alkaloids ubiquitously contain $\mathrm{N}$-methylpiperidine ring or piperidine ring along with one or two substituents at the $\mathrm{C}_{2}$ and/or $\mathrm{C}_{6}$ position of the ring (Felpin and Lebreton, 2004; Folquitto et al., 2019).

One of the major disadvantages of the alkaloids derived from the Lobelia species has been their extreme resemblance in the chemical structures to each other, essentially sharing similar pharmacological, physicochemical, and toxicological profiles which also include cardiotoxicity (Figure 2). The alkaloids in most of the species of Lobelia (with lobeline being the most cited in the literature) are broadly known for presenting medicinal properties against drug abuse, neurological disorder, and respiratory stimulant. The limited medicinal properties of these alkaloids can be attributed to their binding properties at the $\mathrm{nAChR}$ receptors. In this present manuscript, we have only considered the publications where the alkaloid was biologically tested. Unfortunately, the bioactivity characterization of a large majority of those alkaloids was not yet reported and thus excluded. Moreover, to date, more than 80 alkaloids are known to be isolated from different species of Lobelia. The readers are recommended to the following review for the updates on other isolated alkaloids (Folquitto et al., 2019).

\section{Beyond Alkaloids: The Bioactive Components of Other Classes}

Over the years, the isolation and characterization of secondary metabolites derived from Lobelia species have garnered significant attention. It is now an established fact that most species of the genus Lobelia contain different classes of secondary metabolites including but not limited to flavonoids, terpenoids, fatty acids, polyacetylenes, coumarins, neolignans, polysaccharides, and amides in varying concentrations. In recent years, the identifications of these newer compounds also presented the opportunities to address the limited bioactivity of alkaloids mentioned earlier. Due to this fact, growing numbers of literature are being published. In this section, we will present a current account of these newer novel bioactive natural products derived from Lobelia species. A special focus has been given to accounting for the molecular mechanism of these newer secondary metabolites.

Since mid-to end- 20th-century investigations into the pharmacology of components derived from Lobelia species were centered onto the alkaloids. In 1961, Sasaki et al. reported the isolation of a new glucofructan "sessilifolan" from Lobelia sessilifolia Lamb. I. (Sasaki et al., 1961; Sasaki and Mikami, 1962). It was perhaps the first report identifying other secondary metabolites than alkaloids in Lobelia. In 1986, Santosa et al. reported the in vitro as well as in vivo activity of the hot water extract of Lobelia chinensis against Ehrlich ascites tumor and Sarcoma 180 cells (Santosa et al., 1986). However, in subsequent decades, not much progress has been made on characterizing the other classes of secondary metabolites.

Subarnas et al. identified a novel antidepressant bioactive component, $\beta$-amyrin palmitate 10 in an extract of the leaves of Lobelia inflata (Subarnas et al., 1992). Further studies indicated that the antidepressant activity of $\beta$-amyrin palmitate 10 was related to the activation of the noradrenergic system by releasing 
A<smiles>[R]C1CCCC([R])N1C</smiles>

General structure<smiles>CN1[C@H](C[C@H](O)c2ccccc2)CCC[C@@H]1CC(=O)c1ccccc1</smiles>

Lobeline 1

C

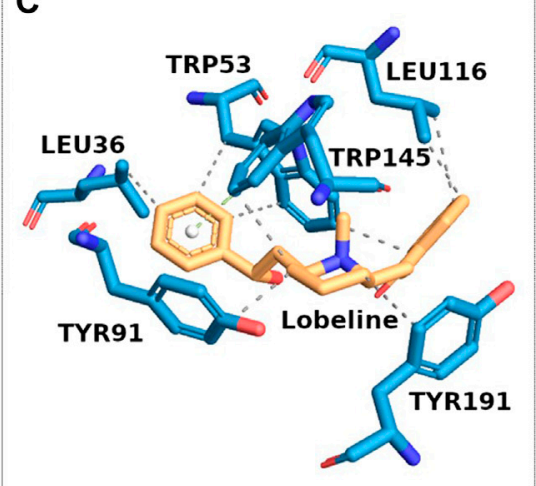

(1)
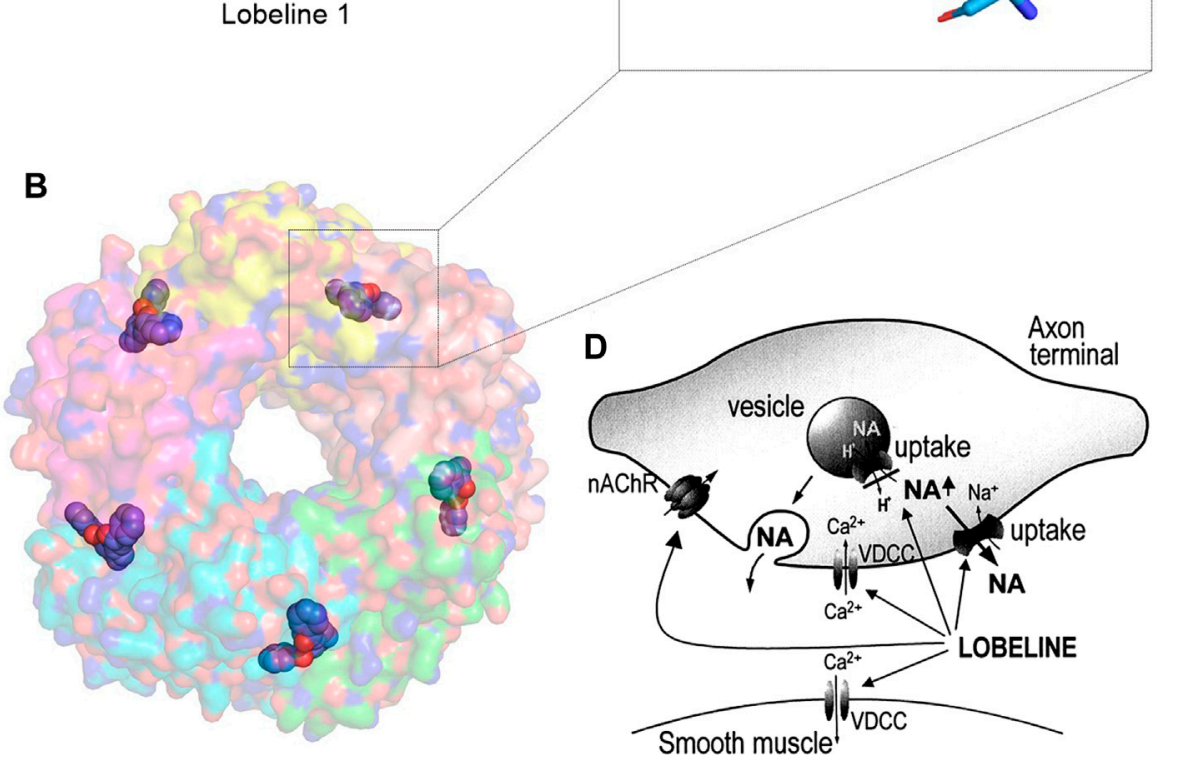

FIGURE 1 | Structure and molecular mechanism of lobeline. (A) Chemical structure. (B, C) Molecular interaction of lobeline bound to the human a 7-nAChR (Spurny et al., 2015). (D) A schematic diagram of the multiple cellular mechanisms of lobeline on the release of norepinephrine taken from the reference (Sántha et al., 2000).

$[3 \mathrm{H}]$ norepinephrine from newly synthesized pools, with mianserin-like action (Subarnas et al., 1993b; Subarnas et al., 1993c). In a forced swimming test, $\beta$-amyrin palmitate at $10 \mathrm{mg} / \mathrm{kg}$ reduced the tetrabenazine-induced $(100$ and $200 \mathrm{mg} / \mathrm{kg}$ ) increase in the duration of the immobility of mice whereas it has shown no effect when treated with alpha-methylpara-tyrosine $(500 \mathrm{mg} / \mathrm{kg})$. Similarly, at 5 and $10 \mathrm{mg} / \mathrm{kg}$, it has decreased the duration of immobility in mice treated with 6hydroxy-dopamine $(50 \mu \mathrm{g} / \mathrm{mouse})$ and desipramine $(15 \mathrm{mg} / \mathrm{kg})$ without showing any effect to the treatment of mice with nomifensine plus 6-hydroxydopamine (Subarnas et al., 1993b). Physicochemically, beta-amyrin palmitate is a water-insoluble, extremely weak basic compound belonging to the triterpenoids compound class which contains six isoprene units. Other studies reported $\beta$-amyrin palmitate exhibiting different pharmacological properties such as induction of hypoactivity by inhibiting alpha 1-adrenoceptors (Subarnas et al., 1993a), anti-diabetic and anti-hyperglycemic activity by blocking the entry of glucose from the intestine (Nair et al., 2014), and antibacterial against Gram-positive and negative bacteria and antifungal activities (Abed et al., 2016).
Recently, Wang et al. reported the identification of four novel flavonoid glycosides, lobelitin A-D 11-14 exhibiting agonistic activities against $\mathrm{G}$ protein-coupled receptor 35 (GPR35) (Wang et al., 2019). The compounds were isolated from Lobelia chinensis.

The authors noticed that lobelitin A-D triggers dosedependent positive signals (monitored for $1 \mathrm{~h}$ ) in dynamic mass redistribution (DMR) agonist assay in varying concentration. For example, at $200 \mathrm{pm}$, lobelitin A, B, and D were recorded exhibiting the largest DMR signal whereas at about $100 \mathrm{pm}$, lobelitin $\mathrm{C}$ exhibited a weaker signal at the maximum concentration of $250 \mu \mathrm{M}$. Based on these results, the authors suggested lobelitin A, B and D as the full agonist and lobelitin C as a partial agonist of GPR35. The structures and the apparent $\mathrm{EC}_{50}$ and $\mathrm{IC}_{50}$ values of lobelitin $\mathrm{A}-\mathrm{D}$ are shown in Figure 3 and Table 1. GPR35 has been implicated in several diseased conditions including hypertension, coronary artery disease, and cancer, and is an area of active research (Divorty et al., 2015; Wei et al., 2017; Quon et al., 2020).

The glucoside 2,6-Dideoxy-7-O-(b- D -glucopyranosyl) 2,6imino- D -glycero- L -gulo-heptitol (7-O- $\beta$-D-glucopyranosyl- 
<smiles>CN1CCCC2C(c3ccccc3)C(C3=NCCCC3)C(c3ccccc3)CC21</smiles>

Lobinaline 2<smiles>CN1C(C[C@@H](O)c2ccccc2)CCC[C@H]1C[C@H](O)c1ccccc1</smiles>

Lobelanidine 3<smiles>CCCCCCCC(O)CC1CCCC(CC(O)CC)N1C</smiles>

Lelobanidine 4<smiles>COc1ccc(C2N[C@H](CO)[C@@H](O)[C@H]2O)cc1O</smiles>

Radicamine A 5<smiles>C[C@H]1N[C@H](c2ccc(O)cc2)[C@H](O)[C@@H]1O</smiles>

Radicamine B 6<smiles>CCCC(O)CC1C=CCC(CC(O)c2ccccc2)N1C</smiles>

Pentylsedinine 7<smiles>CN1C(CCc2ccccc2)CCC[C@H]1CCc1ccccc1</smiles>

Lobelane 8<smiles>CN1[C@H](CCc2ccnc3ccccc23)CCC[C@H]1CCc1ccnc2ccccc12</smiles>

FIGURE 2 | Chemical structures of the bioactive alkaloids derived from Lobelia species.

a-homonojir-imycin, 15) isolated from the methanol extract of the whole plant of Lobelia sessilifolia exhibited potent inhibitory activity against various a-glucosidases (Ikeda et al., 2000). Specifically, 7-O- $\beta$ - D -glucopyranosyl- $\alpha$-homonojir-imycin exhibited an $\mathrm{IC}_{50}$ of 0.25 and $0.27 \mu \mathrm{M}$ against rice and rat intestinal isomaltase $\alpha$-glucosidase, respectively. Additionally, it has also shown the inhibition of porcine kidney trehalase $\left(\mathrm{IC}_{50}=\right.$ $0.013 \mu \mathrm{M})$ and anti-diabetic property (Ikeda et al., 2000).

Kuo et al. reported the antivirus and anti-inflammatory properties of a novel compound lobechine 16 alongwith scoparone (6,7-dimethoxycoumarin) 17 isolated from the methanol extracts of Lobelia chinensis. Lobechine 16 inhibited elastase release with $\mathrm{IC}_{50}$ of $25.01 \pm 6.95 \mu \mathrm{M}$ whereas scoparone 17 inhibited superoxide anion generation with $\mathrm{IC}_{50}$ of $6.14 \pm$ $1.97 \mu \mathrm{M}$ (Kuo et al., 2011).

A neutral polysaccharide (LCPS) 18 was isolated from Lobelia chinensis lour. The monosaccharide composition of LCPS was observed as fructan composed of 2,1-linked- $\beta$-D-fructofuranosyl residue and $\alpha$-D-glu-copyranosyl residue with $\alpha$-D-Glcp- $(1 \rightarrow$ $[1)-\beta$-D-Fruf-(2 $]_{15}$ glycosidic linkage. LCPS was identified as an inulin-type fructan with $2.6 \mathrm{kDa}$ molecular weight with an effective therapeutic option in the treatment of obesity. Oral administration of this inulin alleviated obesity and reduced body weight in high-fat diet-induced mice (Zhang et al., 2020). Specifically, the anti-obesity effects of LCPS evaluated in vivo in male Kunming mice treated with normal chow diet (D12450 J), high fat diet (D12492) and high fat diet plus LCPS $(300 \mathrm{mg} / \mathrm{kg} /$ day) for eight weeks showed $67 \%$ lower body weight gain as compared to high fat diet treatment. High fat diet plus glibenclamide $(5 \mathrm{mg} / \mathrm{kg} /$ day $)$ was used as a positive control which has shown $77 \%$ effect.

$\mathrm{Li}$ et al. isolated another neutral $\alpha$-glucan, named BP1 19 (Mol. weight: $9.45 \mathrm{kDa}$ ), from Lobelia chinensis by hot-water extraction and studied its immunomodulating activities (Li et al., 2016). The authors proposed that $\alpha$-glucan BP1 activates Toll-like receptor 4 (TLR4) and exerts immunomodulating effects such as enhancement of the cell proliferation, nitric oxide production, cytokine secretion and phagocytosis in a dose-dependent manner. Additionally, the glucan also induced cytokine and nitric oxide production mediated by toll-like receptor 4 (TLR4) in RAW 264.7 cells. The backbone of BP1 consisted of alternating units of ${ }_{6} \alpha-D-G l c p^{1}--{ }_{6,3} \alpha-D-G l c p^{1}-\left({ }_{6} \alpha-D-G l c p^{1}\right)$ $\mathrm{x}--\left({ }_{6,3} \alpha-D-\mathrm{Glcp}^{1}\right) \mathrm{y}$. The side chains were $\alpha-D-G l c p{ }^{1}--\left({ }_{6} \alpha-D-\right.$ Glcp $\left.^{1}\right) \mathrm{z}-{ }_{4} \alpha-D-G l c p^{1}{ }_{--} \alpha-D-G l c p^{1}{ }_{--} \alpha-D-G l c p^{1}$ and $\alpha-D-G l c p^{1}$ terminally attached to backbone O-3 of ${ }_{6,3} \alpha-D-$ Glcp $^{1}$ (as shown in Figure 4). Specifically, BP1 demonstrated a dose-dependent induction of proliferation of RAW 264.7 cells at the concentrations of $12.5,25,50$, and $100 \mu \mathrm{g} / \mathrm{ml}$ when administered together with polyB in an MTT assay and tested for $24 \mathrm{~h}$.

Ishimaru et al., isolated two new polyacetylene compounds lobetyolin 20 and lobetyol 21 from the hairy roots of Lobelia inflata (Ishimaru et al., 1991). Recently, He et al. studied the effect of lobetyolin on colorectal cancer (He et al., 2020). They found that lobetyolin induces colon cancer cells by inhibiting the ASCT2-mediated glutamine metabolism. Briefly, they have 


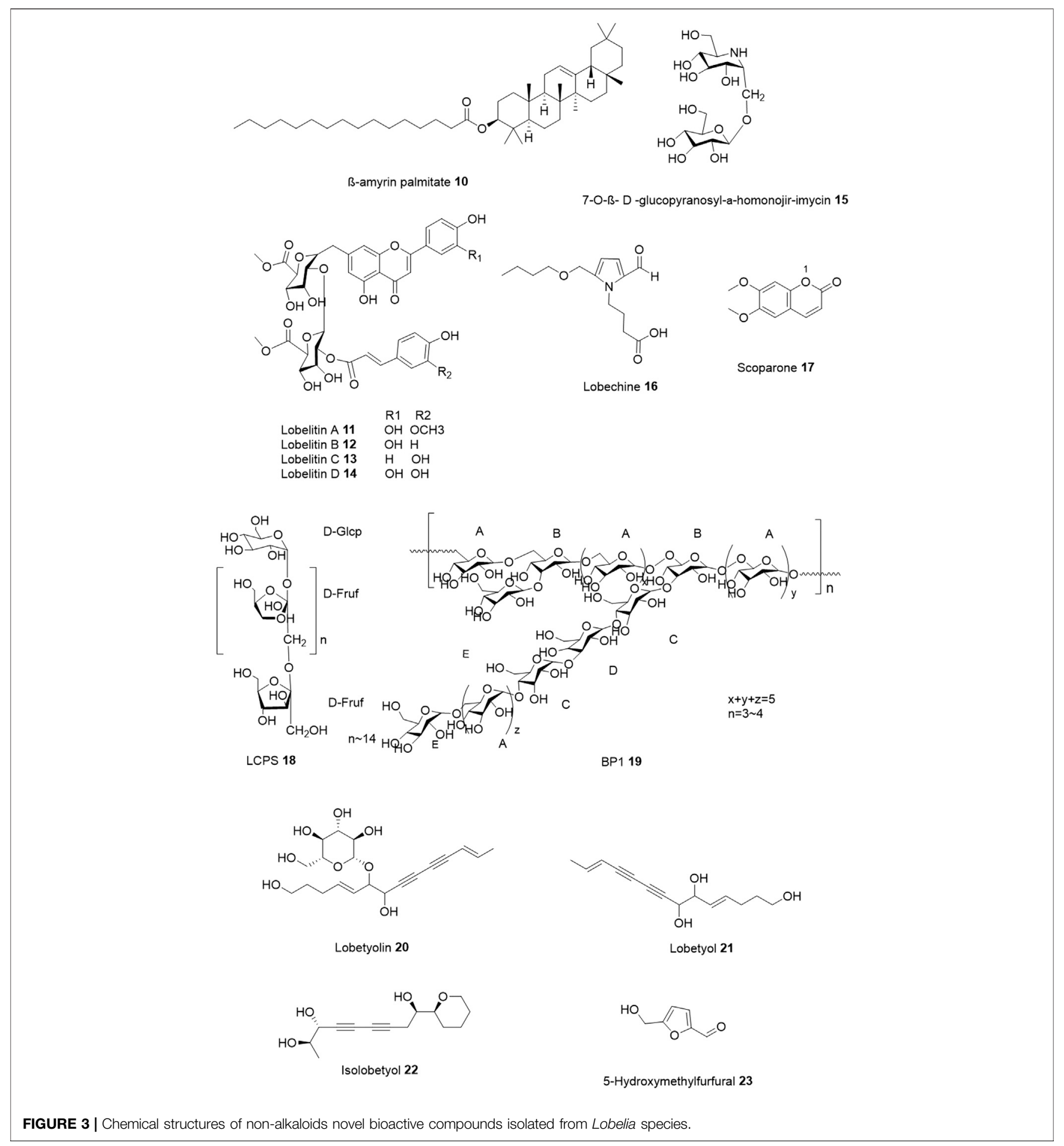

incubated lobetyolin in HCT-116 cells for 3, 6, 12, 18 and $24 \mathrm{~h}$ at varying concentrations of 10,20 and $40 \mu \mathrm{mol} / \mathrm{L}$ in an MTT assay and observed that lobetyolin induces largest inhibitory effect on survival rate at $24 \mathrm{~h}$. On the other hand, the authors did not observe any significant influence in the cell viability in NCM460 cells at 10, 20 and $40 \mu \mathrm{mol} / \mathrm{L}$. Additionally, they observed that lobetyolin at 10,20 , and $40 \mu \mathrm{mol} / \mathrm{L}$ prominently suppresses the expression of ASCT2 protein and reduces the mRNA levels. In addition, lobetyolin at $40 \mu \mathrm{mol} / \mathrm{L}$ also inhibited the expression of ASCT2 in HCT-116 cells. Further, lobetyolin (10, 20, and $40 \mathrm{mg} / \mathrm{kg}$ ) inhibited the tumor volume in the nude (nu/nu) mice transplanted with HCT-116 cells. In another study, Shen et al. 
Zheng et al.

Novel Bioactive Compounds from Lobelia

TABLE 1 | Pharmacological characteristics of active flavonoid glycosides derived from Lobelia chinensis in HT-29 cells (Wang et al., 2019).

\begin{tabular}{lccc}
\hline Compounds & $\mathbf{E C}_{\mathbf{5 0}}(\boldsymbol{\mu} \mathbf{M})$ & $\mathbf{I C}_{\mathbf{5 0}} \mathbf{a}^{\mathbf{a}}(\boldsymbol{\mu} \mathbf{M})$ & $\mathbf{I C}_{\mathbf{5 0}} \mathbf{b}^{\mathbf{b}} \boldsymbol{( \boldsymbol { \mu M } )}$ \\
\hline Lobelitin A & $49.92 \pm 12.61$ & $0.38 \pm 0.08$ & $47.63 \pm 6.31$ \\
Lobelitin B & $18.77 \pm 2.02$ & $0.27 \pm 0.03$ & $27.89 \pm 2.33$ \\
Lobelitin C & Weak & $0.39 \pm 0.21$ & $72.74 \pm 22.96$ \\
Lobelitin D & $67.65 \pm 37.99$ & $0.48 \pm 0.13$ & $64.70 \pm 17.19$ \\
\hline
\end{tabular}

${ }^{a} / C_{50}$ of ML 145 to block the DMR of compounds.

${ }^{b} / C_{50}$ to desensitize the DMR of $1 \mu \mathrm{M}$ zaprinast in HT-29 cells.

reported that lobetyol induces anti-carcinoma effect in MKN45 cells and activates MAPK pathways associated with $\mathrm{G}_{1} / \mathrm{S}$ cell cycle arrest in a time- and dose-dependent manner (Chen et al., 2016). Specifically, the anti-proliferative effect of lobetyol in MKN45 cells was evaluated in an MTT assay at a varying concentration and time ranging from $50 \mu \mathrm{g} / \mathrm{ml}, 75 \mu \mathrm{g} / \mathrm{ml}$, to $110 \mu \mathrm{g} / \mathrm{ml}$ and $12 \mathrm{~h}, 24 \mathrm{~h}$, to $48 \mathrm{~h}$, respectively. Lobetyol demonstrated an $\mathrm{IC}_{50}$ of $71.47 \pm 4.29 \mu \mathrm{g} / \mathrm{ml}$ at $48 \mathrm{~h}$. Further, in MKN45 cells, an increasing dose of lobetyol ranging from 0 , 50 , and $75 \mu \mathrm{g} / \mathrm{ml}$, to $110 \mu \mathrm{g} / \mathrm{ml}$ led to an increase in apoptotic population by $5.5 \%, 13.74 \%, 27.32 \%-31.57 \%$, respectively.

Two other polyacetylene isolobetyol 22 and lobetyol 21 isolated from Lobelia chinensis exhibited moderate cytotoxic activities against MSTO-211H and NCI-H292 cell lines (treated for $48 \mathrm{~h}$ ). Isolobetyol exhibited the $\mathrm{IC}_{50}$ values of 12.36 and $9.31 \mu \mathrm{M}$ against the two cell lines; while the lobetyol showed the $\mathrm{IC}_{50}$ values of 11.76 and $9.64 \mu \mathrm{M}$, respectively (Yang et al., 2014). In contrast, positive control (cisplatin) showed an $\mathrm{IC}_{50}$ of 4.91 and $7.89 \mu \mathrm{M}$ against MSTO$211 \mathrm{H}$ and NCI-H292 cell lines, respectively. However, the authors did not mention at which concentrations the compounds were tested.

In another report, Josh et al. analyzed the essential oil composition of the aerial parts of Lobelia pyramidalis Wall and evaluated their antimicrobial activity (Josh et al., 2011).

A

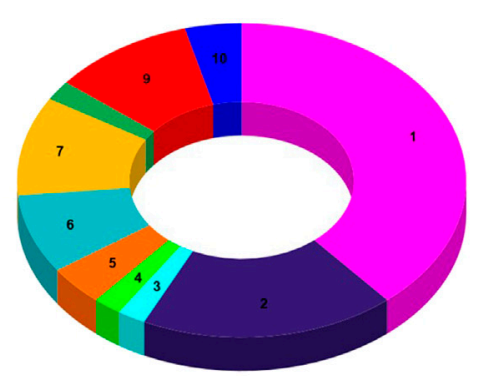

B

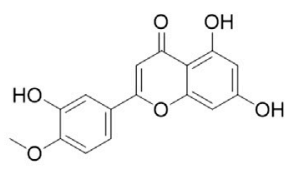

Cluster 1 Diosmetin 24

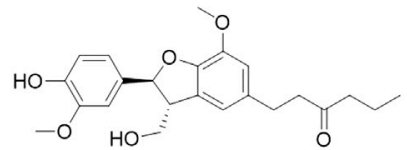

Cluster 2

$(-)(2 R, 3 S)-2,3-d i h y d r o-2-(4-h y d r o x y-3-m e t h o x y$ phenyl)-3-hydroxy-methyl-7-methoxy-5-benzofuran propanoic acid ethyl ester $\mathbf{2 5}$

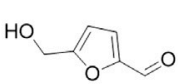

Cluster 3 IMF 26
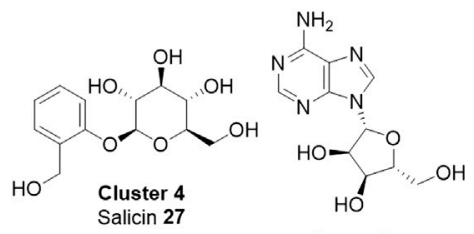

Cluster 5 ADO 28

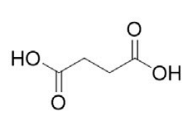

Cluster 6 Succinic acid 29

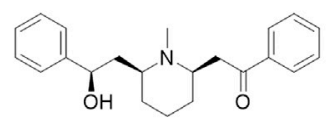

Cluster 7 2-[(2R,6S)-6-[(2R)-2-hydroxy-2-phenylethyl]
-1-methylpiperidin-2-yl]-1-phenylethanone 30
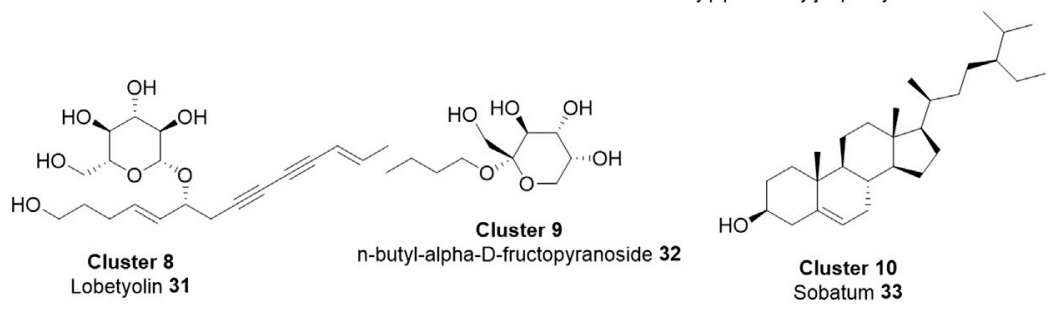

FIGURE 4 | Chemical diversity of the components derived from 17 Lobelia species. (A). The distribution of the chemical compounds in the top 10 clusters based on ECFP4 fingerprint. (B). Chemical structure of the representative compound in individual clusters (Zheng et al., 2020).

Frontiers in Pharmacology | www.frontiersin.org

7

March 2021 | Volume 12 | Article 638210 
TABLE 2 | Lobelia species used in our study to investigate the neuroprotection mechanism.

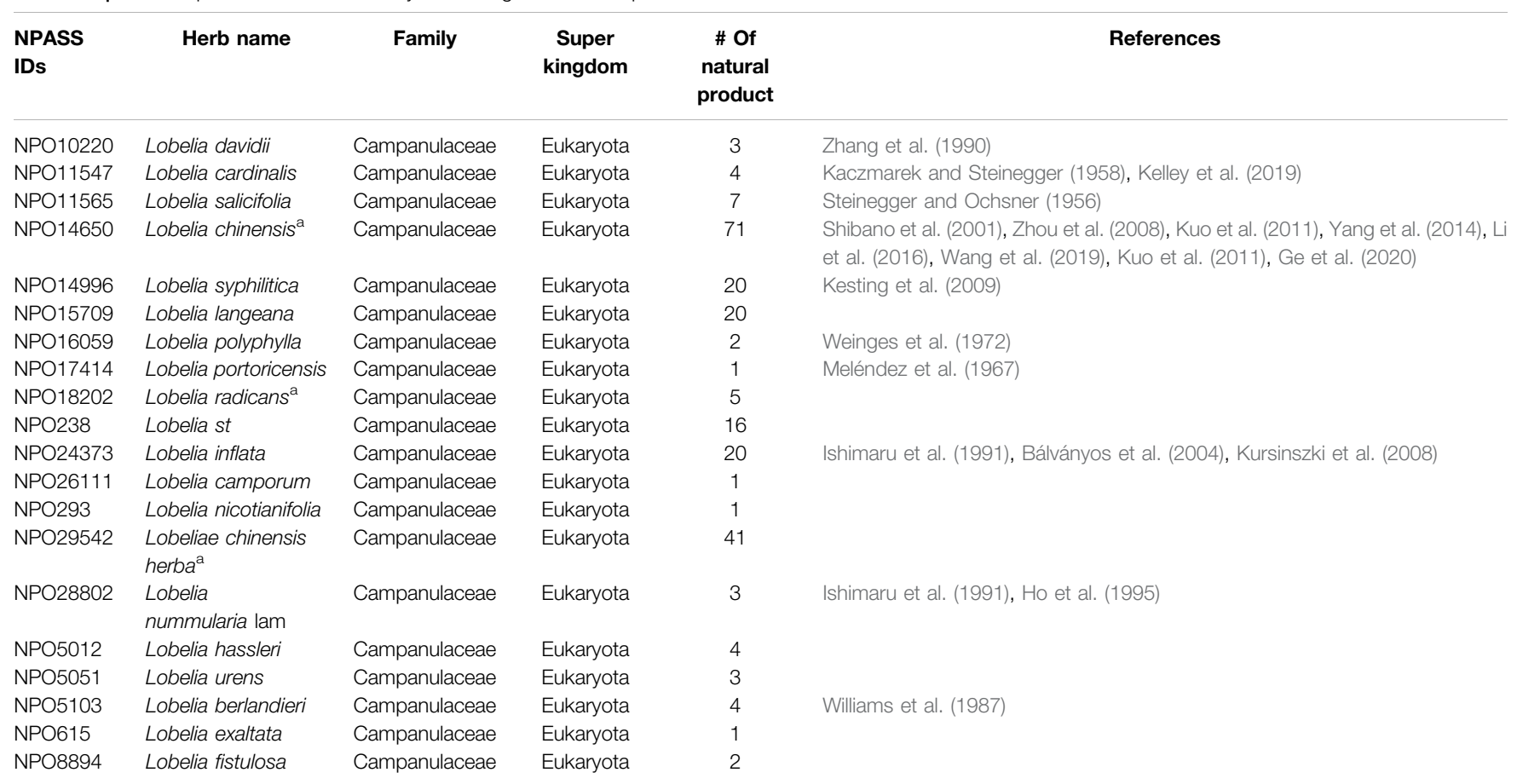

a are the same species with two different entries in NPASS database. (Zeng et al., 2018)

Serial doubling dilutions of the essential oil were prepared from 0.10 to $200 \mathrm{mg} / \mathrm{ml}$ and incubated in Mueller Hinton broth for the bacterial strains at $37^{\circ} \mathrm{C}$ for $24 \mathrm{~h}$. The minimal inhibitory concentration and inhibition zone of $3.12 \mathrm{mg} / \mathrm{ml}$ and $18 \mathrm{~mm}$, respectively was determined against the bacterial strain $S$. aureus. The authors suggested natural terpenoid perilla ketone could be the responsible chemical constituent. However, no further attempt was made to isolate and characterize the compound.

In a recent study, Ma and colleagues identified 208 metabolites of Lobelia chinensis by gas chromatography-mass spectrometer (GC/MS) and conducted a network pharmacology-based investigation of their anti-diabetic mechanism (Ge et al., 2020). Their study revealed that 5-hydroxymethylfurfural 23 acts on GSK3B, TNF, and MAPK1 and affects the insulin resistance signaling pathway as the major mechanism of action. Also, acacetin might act on INSR, DPP4, and GSK3B. No biological evaluation was performed to validate the network pharmacology approach's presented findings, which remains one major drawback of this work.

We have also recently investigated the neuroprotection mechanism of the pharmacokinetically favorable, experimentally validated active compounds derived from the 17 Lobelia species (Table 2) based on network pharmacology and molecular modeling (Zheng et al., 2020). In this work, we also studied the chemical diversity of the validated natural compounds identified in the genus of the Lobelia species including the major components of Lobelia chinensis studied by Ma and Colleagues (Ge et al., 2020).
Fascinatingly, the aglycone part of the flavonoid such as diosmetin and 18 other aglycones constituted the densest cluster indicating their profound presence in the Lobelia species. The representative chemical structure of the top 10 clusters is shown in Figure 4B. We have also not performed the biological evaluations. However, in this review, we intended to summarize the experimentally determined chemical constituents of Lobelia and draw a comparison in their chemical structures (as shown in Figure 4).

\section{Data Sources and Study Selection}

The literature search was performed using PubMed and Scifinder over the period from the beginning of the database until October 2020. Initially, all the literature associated with the search term "Lobelia" were collected. In addition, the databases were also directly searched using the botanical name (e.g., "Lobelia chinensis"). In addition, as a third search strategy, the databases of the major research journals including Science Direct, Frontiers, Wiley, American Chemical Society, MDPI, Springer-Nature, and Taylor and Francis were also searched manually. Articles that have reported only isolation and identification of chemical constituents without biological activities were excluded. No unpublished literature data or conference proceedings were included. Except for a recent systematic review by Folquitto et al. (Folquitto et al., 2019), other articles that described reviews or systematic reviews were excluded. The systematic review by Folquitto et al. was used as an additional strategy to validate the references for the phytochemical details. 


\section{CONCLUSION}

Undoubtedly, Lobelia is an important genus with profound medicinal value. A lot of work has already been done in understanding the pharmacological role of the alkaloids derived from different Lobelia species. Yet, growing investigations on the newer chemical classes indicate that there is certainly an untapped opportunity to obtain bioactive compounds with diverse chemical and pharmacological properties. In this work, we tried to provide the readers the most up-to-date account of the progress made so far, especially toward understanding the molecular mechanism and pharmacological characterizations of the novel bioactive components. Considering the progress being made in the last few years, we believe that this is a timely review to provide the scientific basis for future research aimed at studying the therapeutic potential of the newer chemical compounds derived from the Lobelia species.

\section{REFERENCES}

Abed, S. A., Sirat, H. M., and Taher, M. (2016). Tyrosinase inhibition, antiacetylcholinesterase, and antimicrobial activities of the phytochemicals from Gynotroches axillaris blume. Pak. J. Pharm. Sci. 29, 2071-2078.

Allen, D. D., Lockman, P. R., Roder, K. E., Dwoskin, L. P., and Crooks, P. A. (2003). Active transport of high-affinity choline and nicotine analogs into the central nervous system by the blood-brain barrier choline transporter. J. Pharmacol. Exp. Ther. 304, 1268-1274. doi:10.1124/jpet.102.045856

Andrew, J. (1828). Observations on the use of the Lobelia inflata, in asthma and other spasmodic diseases. Glasg. Med. J. 1, 177-179.

Bálványos, I., Kursinszki, L., Bányai, P., and Szöke, É. (2004). Analysis of polyacetylenes by HPLC in hairy root cultures of Lobelia inflata cultivated in bioreactor. Chromatographia 60, S235-S238. doi:10.1365/s10337-0040188-x

Bell, R. L., Eiler, B. J., Cook, J. B., and Rahman, S. (2009). Nicotinic receptor ligands reduce ethanol intake by high alcohol-drinking HAD-2 rats. Alcohol 43, 581-592. doi:10.1016/j.alcohol.2009.09.027

Billen, B., Spurny, R., Brams, M., van Elk, R., Valera-Kummer, S., Yakel, J. L., et al. (2012). Molecular actions of smoking cessation drugs at $\alpha 4 \beta 2$ nicotinic receptors defined in crystal structures of a homologous binding protein. Proc. Natl. Acad. Sci. USA 109, 9173-9178. doi:10.1073/pnas.1116397109

Brioni, J. D., Decker, M. W., Sullivan, J. P., and Arneric, S. P. (1997). The pharmacology of (-)-nicotine and novel cholinergic channel modulators. Adv. Pharmacol. 37, 153-214. doi:10.1016/s1054-3589(08)60950-3

Brown, D. P., Rogers, D. T., Pomerleau, F., Siripurapu, K. B., Kulshrestha, M., Gerhardt, G. A., et al. (2016). Novel multifunctional pharmacology of lobinaline, the major alkaloid from Lobelia cardinalis. Fitoterapia 111, 109-123. doi:10.1016/j.fitote.2016.04.013

Butler, J. E., Anand, A., Crawford, M. R., Glanville, A. R., McKenzie, D. K., Paintal, A. S., et al. (2001). Changes in respiratory sensations induced by lobeline after human bilateral lung transplantation. J. Physiol. 534, 583-593. doi:10.1111/j. 1469-7793.2001.00583.x

Charlier, R., and Tondeur, R. (1950). [Extraction and pharmacological study of Lobelia suavibracteata (Haumann) alkaloids]. Arch. Int. Pharmacodyn. Ther. 83, 193-195.

Chen, M. W., Chen, W. R., Zhang, J. M., Long, X. Y., and Wang, Y. T. (2014). Lobelia chinensis: chemical constituents and anticancer activity perspective. Chin. J. Nat. Med. 12, 103-107. doi:10.1016/S1875-5364(14)60016-9

da Costa E Silva, L. D., Pereira, P., Regner, G. G., Boaretto, F. B. M., Hoffmann, C., Pflüger, P., et al. (2018). DNA damage and oxidative stress induced by seizures are decreased by anticonvulsant and neuroprotective effects of lobeline, a candidate to treat alcoholism. Metab. Brain Dis. 33, 53-61. doi:10.1007/ s11011-017-0130-1

\section{AUTHOR CONTRIBUTIONS}

QZ developed the idea and the review framework, and wrote the first draft of the manuscript. YW surveyed the literature, collected and validated the data. SZ provided the supervision of the overall work, and did the final editing. All authors contributed to corrections and editing of the subsequent revisions. All authors approve and agree with the content.

\section{FUNDING}

This work was supported by the Program of Survey and Monitoring of Chinese Medicines for National Drugs (No. (2017) 66), Research and Innovation Team of Department of Laboratory Medicine, Hunan University of Medicine (No. 2019-48).

Divorty, N., Mackenzie, A. E., Nicklin, S. A., and Milligan, G. (2015). G proteincoupled receptor 35: an emerging target in inflammatory and cardiovascular disease. Front. Pharmacol. 6, 41. doi:10.3389/fphar.2015.00041

Felpin, F.-X., and Lebreton, J. (2004). History, chemistry and biology of alkaloids from Lobelia inflata. Tetrahedron 60, 10127-10153. doi:10.1016/j.tet.2004. 08.010

Folquitto, D. G., Swiech, J. N. D., Pereira, C. B., Bobek, V. B., Halila Possagno, G. C., Farago, P. V., et al. (2019). Biological activity, phytochemistry and traditional uses of genus Lobelia (Campanulaceae): a systematic review. Fitoterapia 134, 23-38. doi:10.1016/j.fitote.2018.12.021

Ge, Q., Chen, L., Yuan, Y., Liu, L., Feng, F., Lv, P., et al. (2020). Network pharmacology-based dissection of the anti-diabetic mechanism of Lobelia chinensis. Front. Pharmacol. 11. doi:10.3389/fphar.2020.00347

Gedeon, J., and Gedeon, S. (1954). [Alkaloids of lobella nicotianaefolia heyne]. Pharm. Acta Helv. 29, 49-52.

Glover, E. D., Rath, J. M., Sharma, E., Glover, P. N., Laflin, M., Tonnesen, P., et al (2010). A multicenter phase 3 trial of lobeline sulfate for smoking cessation. Am. J. Health Behav. 34, 101-109. doi:10.5993/ajhb.34.1.12

Govind, A. P., Vallejo, Y. F., Stolz, J. R., Yan, J. Z., Swanson, G. T., and Green, W. N. (2017). Selective and regulated trapping of nicotinic receptor weak base ligands and relevance to smoking cessation. Elife 6, e25651. doi:10.7554/eLife.25651

Hart, N., Rocha, A., Miller, D. K., and Nation, J. R. (2010). Dose-dependent attenuation of heroin self-administration with lobeline. J. Psychopharmacol. 24, 51-55. doi:10.1177/0269881108092119

He, W., Tao, W., Zhang, F., Jie, Q., He, Y., Zhu, W., et al. (2020). Lobetyolin induces apoptosis of colon cancer cells by inhibiting glutamine metabolism. J. Cell. Mol. Med. 24, 3359-3369. doi:10.1111/jcmm.15009

Heinzerling, K. (2013). in "Chapter 48-medication development for amphetamine dependence," in Interventions for addiction. Editor P. M. Miller (San Diego, CA: Academic Press), 459-465. doi:10.1016/B9780-12-398338-1.00048-8

Ho, L. K., Ou, J. C., Sun, M. L., and Sun, C. M. (1995). Two rare alkaloids from Pratia nummularia. Planta Med. 61, 567-568. doi:10.1055/s-2006-959376

Ikeda, K., Takahashi, M., Nishida, M., Miyauchi, M., Kizu, H., Kameda, Y., et al. (2000). Homonojirimycin analogues and their glucosides from Lobelia sessilifolia and Adenophora spp. (Campanulaceae). Carbohydr. Res. 323, 73-80. doi:10.1016/s0008-6215(99)00246-3

Ishimaru, K., Yonemitsu, H., and Shimomura, K. (1991). Lobetyolin and lobetyol from hairy root culture of Lobelia inflata. Phytochemistry 30, 2255-2257. doi:10. 1016/0031-9422(91)83624-T

Joshi, S., Mishra, D., Bisht, G., and Khetwal, K. S. (2011). Essential oil composition and antimicrobial activity of Lobelia pyramidalis Wall. EXCLI J. 10, 274-279.

Kaczmarek, F., and Steinegger, E. (1958). [Chromatographic studies on the basic fractions of Lobella cardinalis, especially of lobinaline and the new cardinalis alkaloid 2]. Pharm. Acta Helv. 33, 852-857. 
Kaczmarek, F., and Steinegger, E. (1959). [Paper chromatographic separation of the alkaloids of Lobelia inflata from lobinaline, the main alkaloid of Lobelia cardinalis]. Pharm. Acta Helv. 34, 330-333.

Kelley, Z. D., Rogers, D. T., Littleton, J. M., and Lynn, B. C. (2019). Microfluidic capillary zone electrophoresis mass spectrometry analysis of alkaloids in Lobelia cardinalis transgenic and mutant plant cell cultures. Electrophoresis 40, 2921-2928. doi:10.1002/elps.201900220

Kesting, J. R., Tolderlund, I. L., Pedersen, A. F., Witt, M., Jaroszewski, J. W., and Staerk, D. (2009). Piperidine and tetrahydropyridine alkaloids from Lobelia siphilitica and Hippobroma longiflora. J. Nat. Prod. 72, 312-315. doi:10.1021/ np800743w

Klosa, J. (1953). [Lobelanine synthesis under physiological conditions in the presence of light]. Pharmazie 8, 1030-1032.

Kuo, P. C., Hwang, T. L., Lin, Y. T., Kuo, Y. C., and Leu, Y. L. (2011). Chemical constituents from Lobelia chinensis and their anti-virus and anti-inflammatory bioactivities. Arch. Pharm. Res. 34, 715-722. doi:10.1007/s12272-011-0503-7

Kursinszki, L., Ludányi, K., and Szőke, É. (2008). LC-DAD and LC-MS-MS analysis of piperidine alkaloids of Lobelia inflata $\mathrm{L}$. (In vitro and in vivo). Chromatographia 68, 27. doi:10.1365/s10337-008-0628-0

Lendle, L., and Richter, R. (1950). [Pharmacologic analysis of the emetic and asthmalytic effects of Lobelia tinctures]. Klin. Wochenschr. 28, 665-667. doi:10. 1007/BF01485598

Li, C. Y., Zhao, L. M., Shi, X. W., and Zhang, J. D. (2014). Lobeline shows protective effects against MPTP-induced dopaminergic neuron death and attenuates behavior deficits in animals. Exp. Ther. Med. 7, 375-378. doi:10.3892/etm. 2013.1413

Li, X. J., Bao, W. R., Leung, C. H., Ma, D. L., Zhang, G., Lu, A. P., et al. (2016). Chemical structure and immunomodulating activities of an $\alpha$-glucan purified from Lobelia chinensis lour. Molecules 21, 779. doi:10.3390/molecules21060779

Martin, C. A., Nuzzo, P. A., Ranseen, J. D., Kleven, M. S., Guenthner, G., Williams, Y., et al. (2018). Lobeline effects on cognitive performance in adult ADHD. J. Atten. Disord. 22, 1361-1366. doi:10.1177/1087054713497791

Meléndez, E. N., Carreras, L., and Gijón, J. R. (1967). New alkaloid from Lobelia portoricensis urban. J. Pharm. Sci. 56, 1677-1680. doi:10.1002/jps.2600561234

Miller, D. K., Crooks, P. A., Zheng, G., Grinevich, V. P., Norrholm, S. D., and Dwoskin, L. P. (2004). Lobeline analogs with enhanced affinity and selectivity for plasmalemma and vesicular monoamine transporters. J. Pharmacol. Exp. Ther. 310, 1035-1045. doi:10.1124/jpet.104.068098

Nair, S. A., Sabulal, B., Radhika, J., Arunkumar, R., and Subramoniam, A. (2014). Promising anti-diabetes mellitus activity in rats of $\beta$-amyrin palmitate isolated from Hemidesmus indicus roots. Eur. J. Pharmacol. 734, 77-82. doi:10.1016/j. ejphar.2014.03.050

Nickell, J. R., Krishnamurthy, S., Norrholm, S., Deaciuc, G., Siripurapu, K. B., Zheng, G., et al. (2010). Lobelane inhibits methamphetamine-evoked dopamine release via inhibition of the vesicular monoamine transporter-2. J. Pharmacol. Exp. Ther. 332, 612-621. doi:10.1124/jpet.109.160275

Paz, C., Becerra, J., Silva, M., Burgosa, V., Heydenreich, M., Schmidt, B., et al. (2015). (-)-Pentylsedinine, a new alkaloid from the leaves of Lobelia tupa with agonist activity at nicotinic acetylcholine receptor. Nat. Prod. Commun. 10, 1355-1357.

Quon, T., Lin, L. C., Ganguly, A., Tobin, A. B., and Milligan, G. (2020). Therapeutic opportunities and challenges in targeting the orphan $\mathrm{G}$ protein-coupled receptor GPR35. ACS Pharmacol. Transl. Sci. 3, 801-812. doi:10.1021/acsptsci.0c00079

Raj, H., Bakshi, G. S., Tiwari, R. R., Anand, A., and Paintal, A. S. (2005). How does lobeline injected intravenously produce a cough?. Respir. Physiol. Neurobiol. 145, 79-90. doi:10.1016/j.resp.2004.09.001

Roni, M. A., and Rahman, S. (2017). Lobeline attenuates ethanol abstinenceinduced depression-like behavior in mice. Alcohol 61, 63-70. doi:10.1016/j. alcohol.2017.01.015

Roni, M. A., and Rahman, S. (2015). The effects of lobeline on depression-like behavior and hippocampal cell proliferation following chronic stress in mice. Neurosci. Lett. 584, 7-11. doi:10.1016/j.neulet.2014.10.009

Saldanha, R. V., Cordeiro, E., Costa, E. G., and de Melo, M. E. L. O. (1959). Study of circulatory rate with lobeline (the alkaloid from Lobelia inflata). Arq. Bras. Cardiol. 12, 215-222.

Sántha, E., Sperlágh, B., Zelles, T., Zsilla, G., Tóth, P. T., Lendvai, B., et al. (2000). Multiple cellular mechanisms mediate the effect of lobeline on the release of norepinephrine. J. Pharmacol. Exp. Ther. 294, 302-307.
Santosa, M. H., Herzog, R., and Voelter, W. (1986). Antitumor activity of the hot water extract of Lobelia chinensis. Planta Med. 555, 555. doi:10.1055/s-2007969368

Sasaki, T., and Mikami, M. (1962). [Studies on the components of Lobelia sessilifolia lamb. II. On the periodateoxidation of a new glucofructan "sessilifolan"]. Yakugaku Zasshi 82, 1520-1522.

Sasaki, T., Mikami, M., and Ueda, H. (1961). [Studies on the components of Lobelia sessilifolia Lamb. I. Isolation of a new glucofructan]. Yakugaku Zasshi 81, 1626-1628.

Shen, J., Lu, X., Du, W., Zhou, J., Qiu, H., Chen, J., et al. (2016). Lobetyol activate MAPK pathways associated with G1/S cell cycle arrest and apoptosis in MKN45 cells in vitro and in vivo. Biomed. Pharmacother. 81, 120-127. doi:10.1016/j. biopha.2016.03.046

Shibano, M., Tsukamoto, D., Masuda, A., Tanaka, Y., and Kusano, G. (2001). Two new pyrrolidine alkaloids, radicamines $\mathrm{A}$ and $\mathrm{B}$, as inhibitors of alphaglucosidase from Lobelia chinensis lour. Chem. Pharm. Bull. 49, 1362-1365. doi:10.1248/cpb.49.1362

Spurny, R., Debaveye, S., Farinha, A., Veys, K., Vos, A. M., Gossas, T., et al. (2015). Molecular blueprint of allosteric binding sites in a homologue of the agonistbinding domain of the $\alpha 7$ nicotinic acetylcholine receptor. Proc. Natl. Acad. Sci. USA 112, E2543-E2552. doi:10.1073/pnas.1418289112

Stead, L. F., and Hughes, J. R. (2012). Lobeline for smoking cessation. Cochrane Database Syst. Rev. 2012, CD000124. doi:10.1002/14651858.CD000124.pub2

Steinegger, E., and Egger, F. (1952). [Alkaloids of Lobelia symphilitica L.]. Pharm. Acta Helv. 27, 113-120.

Steinegger, E., and Grutter, H. (1950). [Lurenine, a new crystallized alkaloid from Lobelia urens]. Pharm. Acta Helv. 25, 276-277.

Steinegger, E., and Ochsner, F. (1956). [Alkaloids of Lobelia salicifolia sweet. I]. Pharm. Acta Helv. 31, 89-96.

Subarnas, A., Oshima, Y., Sidikand Ohizumi, Y. (1992). An antidepressant principle of Lobelia inflata L. (Campanulaceae). J. Pharm. Sci. 81, 620-621. doi:10.1002/jps.2600810705

Subarnas, A., Tadano, T., Kisara, K., and Ohizumi, Y. (1993a). An alphaadrenoceptor-mediated mechanism of hypoactivity induced by beta-amyrin palmitate. J. Pharm. Pharmacol. 45, 1006-1008. doi:10.1111/j.2042-7158.1993. tb05649.x

Subarnas, A., Tadano, T., Nakahata, N., Arai, Y., Kinemuchi, H., Oshima, Y., et al. (1993b). A possible mechanism of antidepressant activity of beta-amyrin palmitate isolated from Lobelia inflata leaves in the forced swimming test. Life Sci. 52, 289-296. doi:10.1016/0024-3205(93)90220-w

Subarnas, A., Tadano, T., Oshima, Y., Kisara, K., and Ohizumi, Y. (1993c). Pharmacological properties of beta-amyrin palmitate, a novel centrally acting compound, isolated from Lobelia inflata leaves. J. Pharm. Pharmacol. 45, 545-550. doi:10.1111/j.2042-7158.1993.tb05596.x

Tamboli, A. M., Rub, R. A., Ghosh, P., and Bodhankar, S. L. (2012). Antiepileptic activity of lobeline isolated from the leaf of Lobelia nicotianaefolia and its effect on brain GABA level in mice. Asian Pac. J. Trop. Biomed. 2, 537-542. doi:10. 1016/S2221-1691(12)60092-6

Terry, A. V., Williamson, R., Gattu, M., Beach, J. W., McCurdy, C. R., Sparks, J. A., et al. (1998). Lobeline and structurally simplified analogs exhibit differential agonist activity and sensitivity to antagonist blockade when compared to nicotine. Neuropharmacology 37, 93-102. doi:10.1016/s0028-3908(97)00142-1

Tondeur, R., and Charlier, R. (1950). [Extraction and pharmacological studies of alkaloids of Lobelia giberroa (Hemsl.)]. Arch. Int. Pharmacodyn. Ther. 83, 91-92.

Vartak, A. P., Gabriela Deaciuc, A., Dwoskin, L. P., and Crooks, P. A. (2010). Quinlobelane: a water-soluble lobelane analogue and inhibitor of VMAT2. Bioorg. Med. Chem. Lett. 20, 3584-3587. doi:10.1016/j.bmcl.2010.04.117

Vartak, A. P., Nickell, J. R., Chagkutip, J., Dwoskin, L. P., and Crooks, P. A. (2009). Pyrrolidine analogues of lobelane: relationship of affinity for the dihydrotetrabenazine binding site with function of the vesicular monoamine transporter 2 (VMAT2). J. Med. Chem. 52, 7878-7882. doi:10.1021/jm900770h

Wang, J., Chen, L., Qu, L., Li, K., Zhao, Y., Wang, Z., et al. (2019). Isolation and bioactive evaluation of flavonoid glycosides from Lobelia chinensis Lour using twodimensional liquid chromatography combined with label-free cell phenotypic assays. J. Chromatogr. A. 1601, 224-231. doi:10.1016/j.chroma.2019.04.073

Wei, L., Wang, J., Zhang, X., Wang, P., Zhao, Y., Li, J., et al. (2017). Discovery of $2 \mathrm{H}$-Chromen-2-one derivatives as $\mathrm{G}$ protein-coupled receptor-35 agonists. J. Med. Chem. 60, 362-372. doi:10.1021/acs.jmedchem.6b01431 
Weinges, K., Bähr, W., Ebert, W., and Kloss, P. (1972). [Norlobelanidine, the main alkaloid from Lobelia polyphylla Hook and Arn]. Justus Liebigs Ann. Chem. 756, 177-180. doi:10.1002/jlac.19727560119

Williams, H. J., Ray, A. C., and Kim, H. L. (1987). DELTA.3-Piperideine alkaloids from the toxic plant Lobelia berlandieri. J. Agric. Food Chem. 35, 19-22. doi:10. 1021/jf00073a005

Wu, J., Liu, Q., Yu, K., Hu, J., Kuo, Y. P., Segerberg, M., et al. (2006). Roles of nicotinic acetylcholine receptor beta subunits in function of human alpha4-containing nicotinic receptors. J. Physiol. 576, 103-118. doi:10.1113/jphysiol.2006.114645

Yang, S., Shen, T., Zhao, L., Li, C., Zhang, Y., Lou, H., et al. (2014). Chemical constituents of Lobelia chinensis. Fitoterapia 93, 168-174. doi:10.1016/j.fitote.2014.01.007

Zeng, X., Zhang, P., He, W., Qin, C., Chen, S., Tao, L., et al. (2018). NPASS: natural product activity and species source database for natural product research, discovery and tool development. Nucleic Acids Res. 46, D1217-D1222. doi:10. 1093/nar/gkx1026

Zhang, M.-Z., Wang, J.-C., and Zhou, S.-H. (1990). Alkaloids triterpenoids of Lobelia davidii. Phytochemistry 29, 1353-1354. doi:10.1016/0031-9422(90)85468-U

Zhang, X., Hu, P., Zhang, X., and Li, X. (2020). Chemical structure elucidation of an inulintype fructan isolated from Lobelia chinensis lour with anti-obesity activity on dietinduced mice. Carbohydr. Polym. 240, 116357. doi:10.1016/j.carbpol.2020.116357

Zheng, G., Dwoskin, L. P., and Crooks, P. A. (2006). Vesicular monoamine transporter 2: role as a novel target for drug development. AAPS J. 8, E682-E692. doi:10.1208/aapsj080478
Zheng, G., Dwoskin, L. P., Deaciuc, A. G., Norrholm, S. D., and Crooks, P. A. (2005). Defunctionalized lobeline analogues: structure-activity of novel ligands for the vesicular monoamine transporter. J. Med. Chem. 48, 5551-5560. doi:10. 1021/jm0501228

Zheng, Q., Fang, L., Huang, X., Wang, Y., and Zhang, S. (2020). Investigation of the mechanisms of neuroprotection mediated by Lobelia species via computational network pharmacology and molecular modeling. Res. Sq. doi:10.21203/rs.3.rs$61537 / \mathrm{v} 1$

Zhou, Y., Wang, Y., Wang, R., Guo, F., and Yan, C. (2008). Two-dimensional liquid chromatography coupled with mass spectrometry for the analysis of Lobelia chinensis Lour. using an ESI/APCI multimode ion source. J. Sep. Sci. 31, 2388-2394. doi:10.1002/jssc.200700685

Conflict of Interest: The authors declare that the research was conducted in the absence of any commercial or financial relationships that could be construed as a potential conflict of interest.

Copyright (c) 2021 Zheng, Wang and Zhang. This is an open-access article distributed under the terms of the Creative Commons Attribution License (CC BY). The use, distribution or reproduction in other forums is permitted, provided the original author(s) and the copyright owner(s) are credited and that the original publication in this journal is cited, in accordance with accepted academic practice. No use, distribution or reproduction is permitted which does not comply with these terms. 